\title{
Advantage of the regenerative potentials of the periosteum especially in children, Oghara experience: A case series
}

\author{
*Enemudo, R.E.T ${ }^{1}$, Odatuwa-Omagbemi, D.O. ${ }^{1}$, Edomwonyi, E.O ${ }^{2}$, Obumse, A.T. ${ }^{1}$, \\ Akpojevwe E.O. ${ }^{1}$
}

\begin{abstract}
The periosteum is a composite tissue comprising an outer protective fibrovascular layer and an inner cambium regenerative pluripotent layer. The regenerative function of periosteum has been put to clinical use by dental surgeons to manage alveolar ridge reduction and by tissue engineers to produce autologous micrograft and collagen used to manage complex wounds and scars. The essence of this study is to add to the body of knowledge on clinical use of periosteum to treat bone defects from the orthopaedic perspective. We highlight a case series to demonstrate the use of periosteum in managing bone defects caused by benign bone tumour, chronic osteomyelitis, tibial hemimelia and traumatic bone loss of the distal tibia in Delta State University Teaching Hospital, Oghara. Treatment of bone defects by this means is cost effective and the outcome is very satisfactory.
\end{abstract}

Key words; Periosteum, mesenchymal stem cells, bone defects, distraction histiogenesis.

*Corresponding author

Enemudo, R.E.T

ORCID-NO: http://orcid.org/0000-0003-3830-0933

Email: royenemudo11@gmail.com

${ }^{1}$ Delta State University Teaching Hospital, Oghara, Nigeria

${ }^{2}$ Irrua Specialist Teaching Hospital, Irrua, Nigeria 


\title{
Avantage des Potentiels Régénératifs du Périoste en Particulier Chez les Enfants, Expérience Oghara - Une série de Cas
}

\author{
*Enemudo, R.E.T ${ }^{1}$, Odatuwa-Omagbemi, D.O ${ }^{1}$, Edomwonyi, E.O ${ }^{2}$, Obumse, A.T. ${ }^{1}$, \\ Akpojevwe E.O. ${ }^{1}$
}

\begin{abstract}
Résumé
Le périoste est un tissu composite comprenant une couche fibrovasculaire protectrice externe et une couche pluripotente régénératrice du cambium interne. La fonction régénératrice du périoste a été utilisée en clinique par les chirurgiens-dentistes pour gérer la réduction de la crête alvéolaire et par les ingénieurs tissulaires pour produire des microgreffes autologues et du collagène utilisés pour gérer les plaies et les cicatrices complexes. L'essence de cette étude est d'ajouter à l'ensemble des connaissances sur l'utilisation clinique du périoste pour traiter les défauts osseux du point de vue orthopédique. Nous mettons en évidence une série de cas pour démontrer l'utilisation du périoste dans la gestion des défauts osseux causés par une tumeur osseuse bénigne, une ostéomyélite chronique, un tibialhemimelia et une perte osseuse traumatique du tibia distal au Delta State University Teaching Hospital, Oghara. Le traitement par ce moyen est rentable et le résultat est très satisfaisant.
\end{abstract}

Mots-clés : Périoste, cellules souches mésenchymateuses, défauts osseux, histiogenèse par distraction.

\author{
*Corresponding author \\ Enemudo, R.E.T \\ ORCID-NO: http://orcid.org/0000-0003-3830-0933 \\ Email:royenemudo11@gmail.com \\ ${ }^{1}$ Delta State University Teaching Hospital, Oghara, Nigeria \\ ${ }^{2}$ Irrua Specialist Teaching Hospital, Irrua, Nigeria
}

Research Journal of Health Sciences subscribed to terms and conditions of Open Access publication. Articles are distributed under the terms of Creative Commons Licence (CC BY-NC-ND 4.0). (http://creativecommons.org/licences/by-nc-nd/4.0).

http://dx.doi.org/10.4314/rejhs.v8i2.8 


\section{INTRODUCTION}

Periosteum is a composite tissue that lines the surface of bone excluding the articular cartilage $(1,2)$. It is made up of an outer fibrous tissue and an inner cambium layer $(1,2)$. The fibrous tissue layer contains fibroblast, perivascular and neural cells $(1,2)$. The fibrovascular outer layer accounts for the protective function of the periosteum $(1,2)$. The cambium inner layer, on the other hand, contains pluripotent mesenchymal stem cells (MSCs) and growth factors that modulate the activities of the MSCs (1). The cambium layer is responsible for the regenerative function of the periosteum $(1,2)$. In osteogenesis, these cells transform to osteoblast cells that regenerate bone (1). The regenerative ability of the periosteum is highest in children and weakens as age progresses (2).

Historically, Duhamel was the first to report that disturbance of periosteum led to formation of new bone in 1742 (3) while Ollier discovered that transplanted periosteum was capable of inducing new bone formation (4). Over the years, it has been realized that periosteum contains cells that participate in endochondral bone formation prenatally and in fracture healing after birth (5). This has led maxillofacial surgeons and tissue engineering researchers to take advantage of the regenerative potential of periosteum to successfully treat bone defects that were hitherto difficult to treat $(5,6,7)$.

There is paucity of literature that discussed the usefulness of periosteum in the field of orthopaedics locally, hence we present our experience on how we took advantage of the regenerative potential of the periosteum to manage bone defects arising from different causes in children in Delta State University Teaching Hospital, Oghara, Delta State, Nigeria.

\section{METHODS AND MATERIALS}

This is a retrospective study highlighting a series of four case presentations showing bone defects arising from different causes and managed with periosteum, utilising the regenerative potential of periosteum in Delta State University Teaching Hospital. The study was over a 3-year period, from May 2013-April 2015. Information was obtained from case notes of patients, who were children (age range of 2-4 years). Those who had bone defects from different causes like excised bone tumour, sequestrectomy, traumatic bone loss and following treatment for congenital causes that were treated by means of periosteum only were included. Those with bone defects treated with bone graft or its substitutes were excluded in this study. Consent was obtained from the parents of the patients used for the study. Ethical clearance for the study was obtained from the institution research ethical committee.

\section{CASE 1}

A 3year old boy had a painful pathological fracture of the midshaft of the left humerus from a suspected benign bone tumour occupying the middle third of the shaft. An open subperiosteal excision biopsy of the affected middle third was done and the remaining proximal and distal thirds of humeral fragments were supported by an external fixator device to ensure the bridging periosteum length was fully stretched out to prevent loss of bone length. This was further reinforced with Plaster of Paris (POP) cast to protect the regenerate in case of possible pin loosening and pins pulling out before consolidation of the regenerate occurred, as the humerus was weakened by the disease process. The patient was discharged after 5days post operation and managed on an out-patient basis afterwards. Pins were noticed to be backing out by the $3^{\text {rd }}$ week post operation; therefore, the external fixator was then removed. The biopsy specimen sent for histology was confirmed to be a benign bone cyst which showed cyst with clear fluid lined by thin fibrous membrane. The membrane contained osteoid. An x-ray was done at 4 th week post-operation showing regeneration of new bone at the site of the defect of tumour excision. The plaster of Paris cast was removed at 4 th week post operation. The child was able to abduct the shoulder joint and keep the upper limb in a horizontal position without support. The boy has been doing well since then. [Fig 1a, 1b, 1c and 1d]

\section{CASE 2}

A 3year old boy was running after the mother, who was crossing the road, unknown to her that her son was running after her. An oncoming bus on a high speed ran over the child's leg. This led to severe comminution and extrusion of the distal tibia (Gustilo type 3b). There was laceration of the skin and underlying soft tissue in the process. There was no associated neurovascular injury. X-ray done confirmed missing distal third of the tibia but an intact fibula. An immediate debridement was done and the limb was put in a protective above knee plaster of Paris back slab and later a scotch cast with a window for wound dressing. The foot was kept in a plantigrade position to prevent the foot 
from developing a clubfoot deformity. The patient was discharged home after 2 weeks of admission and treatment continued in the outpatient clinic. Patient started partial weight ambulation from the $3^{\text {rd }}$ week. After 6weeks of cast protection, a new tibia bone had regenerated at the tibia defect. The child subsequently ambulated without any form of cast protection and has been doing well. [Fig 2a, 2b, 2c]

\section{CASE 3}

A 4year old boy was managed for chronic osteomyelitis of the proximal three quarter of the right tibia bone. This followed a traumatic fracture injury of the right leg that was initially managed by a traditional bone setter. Patient was initially very ill and was discharging pus from several sinuses. After a course of antibiotics that was based on based on sensitivity (Ceftriaxone for 2 weeks and later cefuroxime for 4 weeks and metronidazole for 6 weeks) and blood transfusion, his condition improved. An x-ray that was done showed the presence of involucrum, sequestrum and cloaca. Sequestrectomy was done. This led to the removal of the sequestrated tibia that involved the proximal three-fourth of the tibia. The limb was subsequently put in a cast. After 8 weeks, a repeat $\mathrm{x}$-ray was done and it showed that the involucrum had increased and well consolidated.

\section{CASE 4}

A 2-year-old boy was managed for a type 2 tibia hemimelia by means of Ilizarov technique after the option of amputation and prosthetic fittings was declined. A free fibula graft from the distal half excluding the physis and epiphysis area was harvested subperiosteally from the ipsilateral leg and used to bridge the tibia defect with a k-wire. The defect created by the harvested fibula was filled up by fibula bone regenerated from the periosteum stripped from the harvested fibula segment. The transplanted fibula tibialized over time following weight bearing. The child now has both distal tibia and fibula. [Fig 3a-3e]

\section{DISCUSSION}

The bones of growing children are predisposed to various diseases and injuries like that seen in adults. The treatment modalities given to these problems need to be modified because of the advantage provided by the regenerative ability of the periosteum. Injury or insult can arise from tumours causing pathological fractures, chronic osteomyelitis leading to sequestrum formation that may involve the whole shaft. Fracture injury in areas known to have precarious blood supply and lead to bone necrosis in adult bone have been known to survive in children because of the resilience of periosteum in children (6).

In adult bone, treatment modalities have been established to address some of these problems. These are not without their drawbacks. For example, a patient that has a benign bone tumour in a large segment like that in Case 1, will require the use of fillers like bone cement, allografts and autologous bone graft $(5,7)$. Some of the fillers are foreign bodies that can predispose the patient to infection and other morbidities $(5,7,8)$. In the future, there may be need to carry out other surgeries to remove the foreign body to control infection. Autologous bone graft, that is the gold standard in filling defects, is limited by the small amount available $(5,7,8)$. There is also the problem of morbidity suffered at the donor site. The quality of the graft tends to depreciate with time because it has been isolated from its primary blood supply and nourishment from the recipient site may not be adequate $(5,7,8)$. In a situation where the defect is too large and there is no effective means of filling such defects, amputation of the limbs has been done and prosthetic fittings used to replace the defects $(9,10)$. This option has its own psychological problem associated with it $(9,10)$. The use of a simple external device as shown in Case 1, used to manage the defect created by the tumour excision, was just enough to provide the necessary support for the periosteum while it regenerates new bone to fill up the defect, thus obviating the conventional treatment modalities used to manage such defects enumerated above and the associated morbidities and complications.

Distraction histiogenesis procedure used to create new bone and other soft tissues to fill up defects utilizes the regenerative potential of periosteum by the principle of tension-stress $(11,12,13)$. Here, periosteum is stretched out to cover the area of defect to grow new bone $(11,13)$. When this is achieved, new bone is generated by the periosteum to fill the defect $(11,13)$. This procedure is effective in both children and adults $(11,13)$. A stable construct like linear rail system or Ilizarov device is needed to provide support for the periosteum while it regenerates the new bone and during the period the new bone formed eventually consolidates (13). It is important to emphasize the importance of the effective splint used to support the periosteum during the process of regeneration and consolidation of the new 
bone. In this study, these were provided by an external fixator, scotch cast and linear rail system. Poor stability of the periosteum can lead to collapse of the regenerate from folding of the periosteum if it is not fully stretched out and properly supported (13). There could be bending or malrotation of the eventual new bone formed. This has been reported by several authors $(11,13)$.

The use of periosteum is very cheap in the treatment options used in this study. Distraction histiogenesis, though may appear relatively expensive, time consuming and the learning curve takes time to attain, however, the gains far outweighs the option of amputation previously used to treat such large defects (1113). The patients that are able to go through it are very happy and satisfied with the outcome (11). Typical example is the patient that was managed for tibial hemimelia. The parents accepted distraction histiogenesis and declined the option of amputation which was an alternative treatment for the condition. They were very happy with the treatment outcome. Hosny, in his article on treatment options of tibial hemimelia in Egypt, said parents preferred the Ilizarov treatment option to amputation because of the negative psychological effect associated with loss of a limb (10).

Periosteum derived progenitor cells (PDPCs) have been put into a lot of clinical uses in cartilage regeneration, oral maxillofacial tissue engineering (5). d'Aquino et al designed Rigenera, a biocomplex containing a periosteum derived micrograft and collagen, used by dental surgeons to prevent reduction of vertical and horizontal dimensions of the alveolar ridge ${ }^{5}$. It has also been used to treat complex wounds and pathological scars $(5,6,7)$.

Dror Paley, in his write up on Congenital Pseudoarthrosis, and other authors revealed that the cause of the pathology was due to presence of fibrous hamartoma in the periosteum that has low osteogenicity and high osteoclastogenicity $(14,15)$.? Cure was possible if this defective periosteum and pseudoarthrosis were excised and replaced by a viable periosteal graft and augmented with cancellous bone graft harvested from iliac crest $(14,15)$.

The child with chronic osteomyelitis that had sequestrectomy, only needed cast to provide support for the periosteum to regenerate new bone to replace the removed sequestrum. The child is saved from incurring cost and morbidities associated with the alternative of fibula transplant often used in adult patients with similar loss of extensive length of bone. This is vascularized fibula transplant, a procedure requiring plastic surgery expertise (12). This service is not readily available and the outcome is not certain in view of the underlying septic focus.

There is always an advantage in opting for the natural body parts as much as possible than grafted artificial substitutes because of the blood supply they carry which the artificial substitutes do not have (5). The blood supply they have, also affords them the ability to fight infection effectively. Periosteum provides this advantage (5).

Poverty does not provide the managing surgeon the opportunity or room for several surgeries needed to solve surgical problems patients may have. The duration of stay in hospital was very short in the patient with humeral bone tumour and the child with the traumatic distal tibia bone loss. They spent 5 and 14 days respectively as their condition could be managed after surgery and were discharged to the out-patient clinic. This also saved cost. There is, therefore, the need to develop treatment modalities like that afforded by the use of the regenerative ability of the periosteum to effectively save cost.

\section{CONCLUSION}

The periosteum of the bones of growing children is very versatile and resilient in overcoming insults and injuries posed by diseases and trauma $(3,6)$. They are able to recover and regenerate missing, damaged or excised bone parts with treatment methods that are extremely cost effective. There is a need to take advantage of this special qualities of periosteum in bones of growing children and even apply it to similar situations in adults. Fortunately, distraction osteogenesis has provided this opportunity for adults as well.

\section{Conflict of Interest: None.}

Acknowledgement: We wish to appreciate the nurses in the Department of Orthopaedics and Trauma and physiotherapists of the Delta State University Teaching Hospital, Oghara that participated in the care of these patients and made the treatment outcome very successful.

\section{REFERENCES}

1. d'Aquino R, Trovato L, Graziano A, Ceccarelli G, et al. Periosteum derived micro-grafts for tissue regeneration of Human Maxillary bone. Journal of Translational Science 2016; 2(2):125-29.

2. Dwek JR. The Periosteum: What is it, where is it, and what mimics it in its absence? Skeletal 
Radiology 2010;39(4):319-23

3. Concise Review: The Periosteum; Tapping into a Reservoir of Clinically Useful Progenitor Cells. Stem Cell Transl. Med.2012; 1(6):480-91. [Cross Ref]

4. Shapiro F. Bone development and its relation to fracture repair. The role of mesenchymal osteoblasts and surface osteoblasts. Eur Cell Mater. 2008; 15:53-76.]

5. Knothe Tate ML, Ritzman TF, Schneider E, et al. Testing of a new one-stage bone-transport surgical procedure exploiting the periosteum for the repair of long-bone defects. J Bone Joint Surg Am. 2007; 89:307-316.

6. Modric J. "Periosteum". eHealthStar. Retrieved 15 June 2017.

7. Arnsdorf EJ, Jones LM, Carter DR, Jacobs CR. The Periosteum as a Cellular source for functional tissue engineering. Tissue Eng. Part A. 2009; 15(9): 2637-42.

8. Ferretti C, Mattioli-Belmonte M (2014) Periosteum derived stem cells for regenerative medicine proposals: Boosting current knowledge. World J Stem Cells 6: 266-277.

9. Hosny GA. Treatment of Tibial hemimelia without amputation. J. Paediatric Orthop. B.2005;14(4):250.
10. Enemudo RE. Management of Tibial hemimelia: A Case Report. Nigerian Journal of Orthopaedics and Trauma.2013;12(2):128-33.

11. Enemudo RET, Odatuwa-Omagbemi DO, Otene CI, Emina BK, Onyeokweanwa CE. Distraction Osteogenesis in the Management of Bone Gaps. Nigeria Journal of Orthopaedics and Trauma. 2013;12(2):107-112.

12. Gurdayal SK, Pradeep G, Pradeep KS. Reconstruction of post traumatic long bone defects with vascularized fibula. A series of 28 cases. India J. of Plastic Surgery. 2013; 46(3):54346.

13. Yongu and Isa. Femoral lengthening using Ilizarov Technique in Nigeria: National Orthopaedic Hospital Dala Experience. Nig Journal of Orthop and Trauma. 2010;9 (2):58-60

14. Ahmed MT, Paley D, Kocaoglu M, Eralp L, Herzenberg JE, Ergin ON. Periosteal grafting for Congenital Pseudoarthrosis of Tibia: A Preliminary Report. Clinical Orthop. Related Res. 2008; 466(12): 2981-94

15. Lee DY, Cho TJ, Lee HR, Lee k et al. Disturbed Osteoblastic differentiation of Fibrous Hamartoma cells from Congenital Pseudoarthrosis of the tibia associated with Neurofibromatosis type I. Clinical Orthop. Surg. 2011;3(3):230-7. 


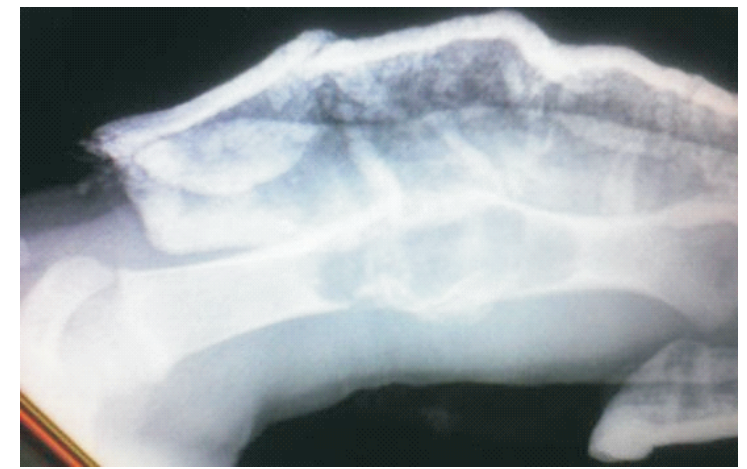

Figure 1a: Right humerus with bone cyst in cast

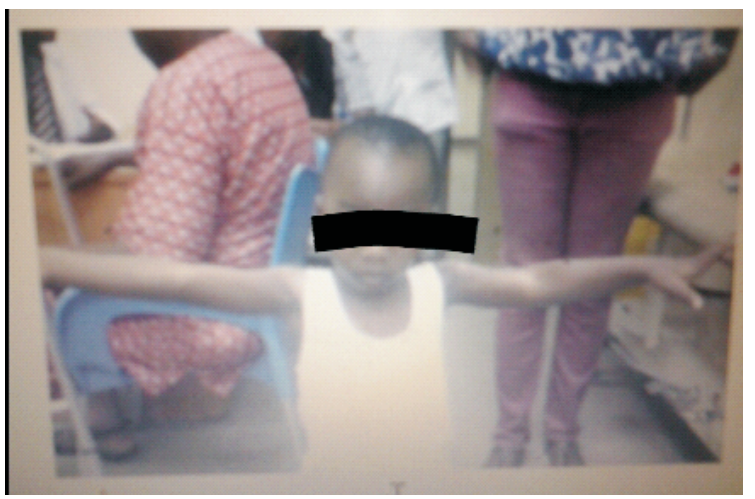

Figure 1c: Upper limb abducted post-operation.

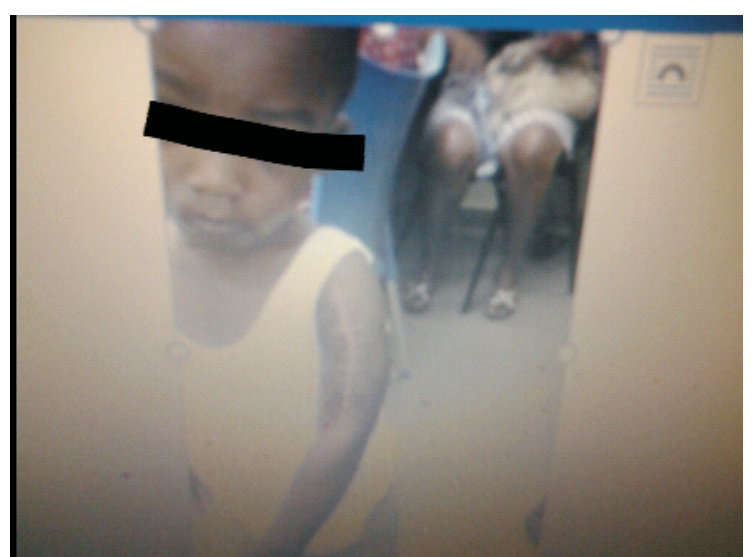

Figure 1d: left arm showing post-operative scar.

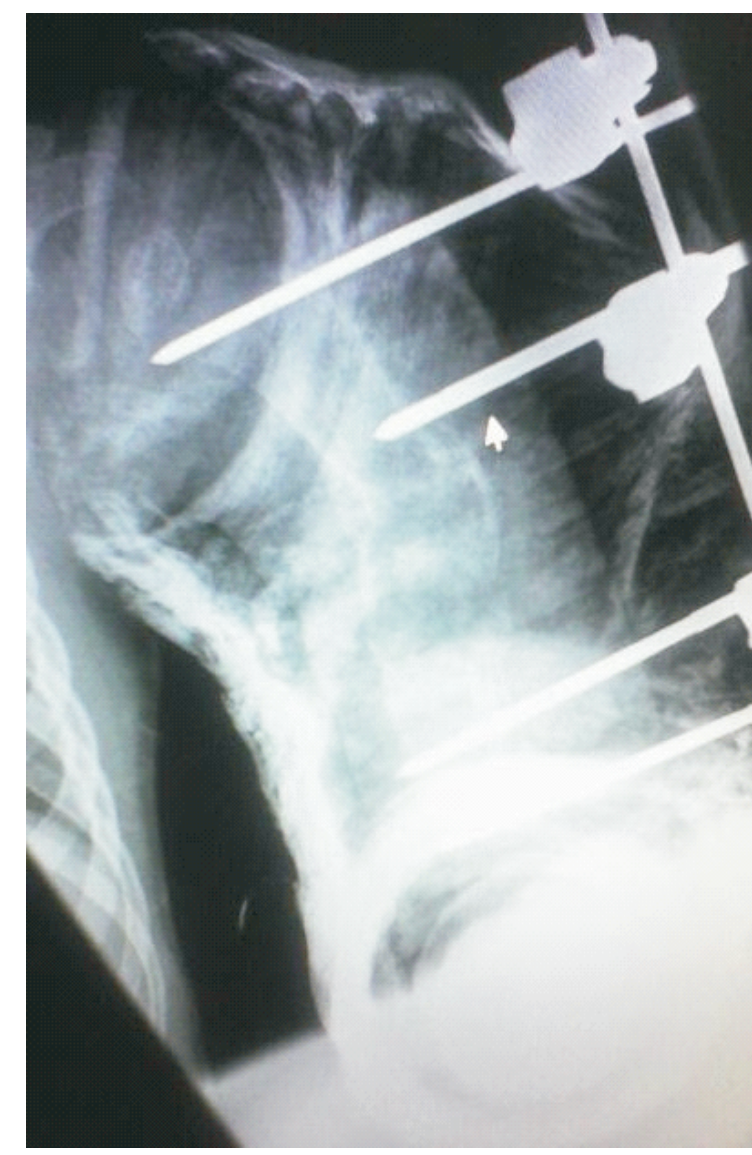

Figure 1b: Post excision biopsy with external fixator in situ

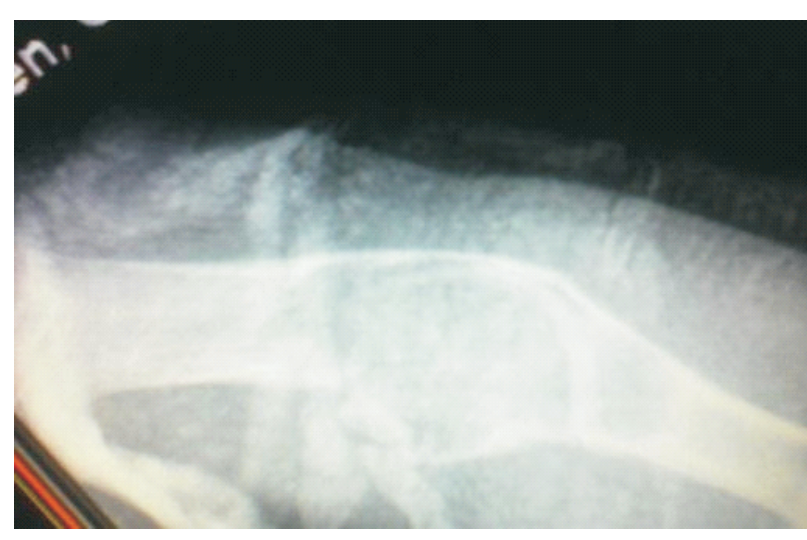

Figure 1e: Post-operation X-ray showing regeneration 


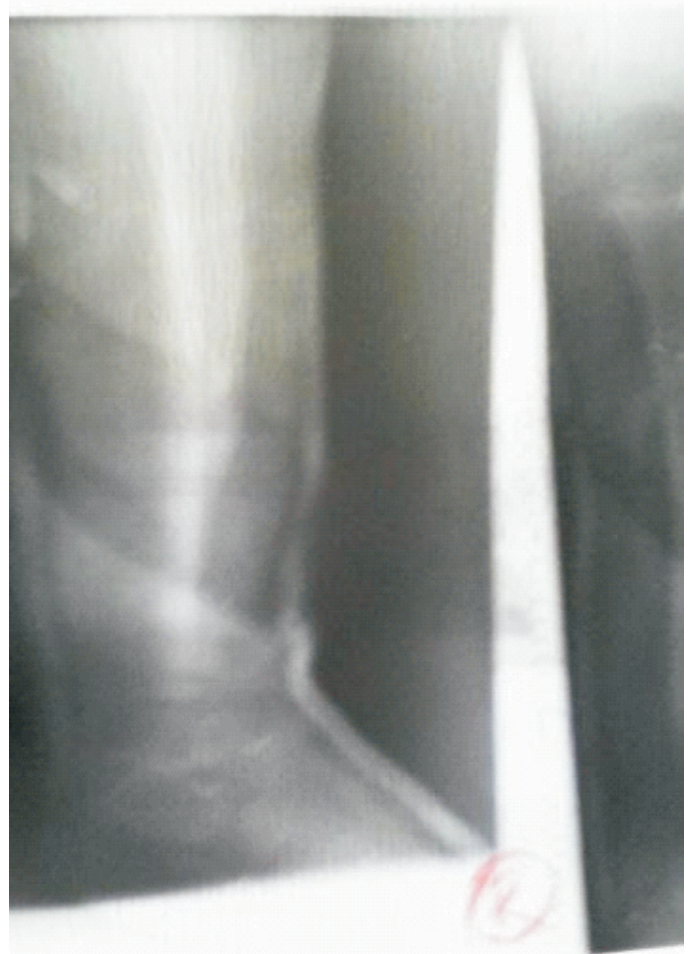

Figure 2a: X-ray showing missing distal labia

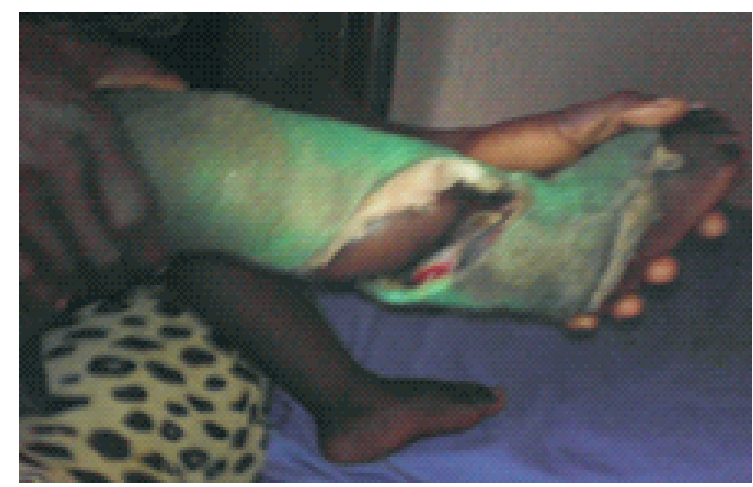

Figure 2b: Leg in cast

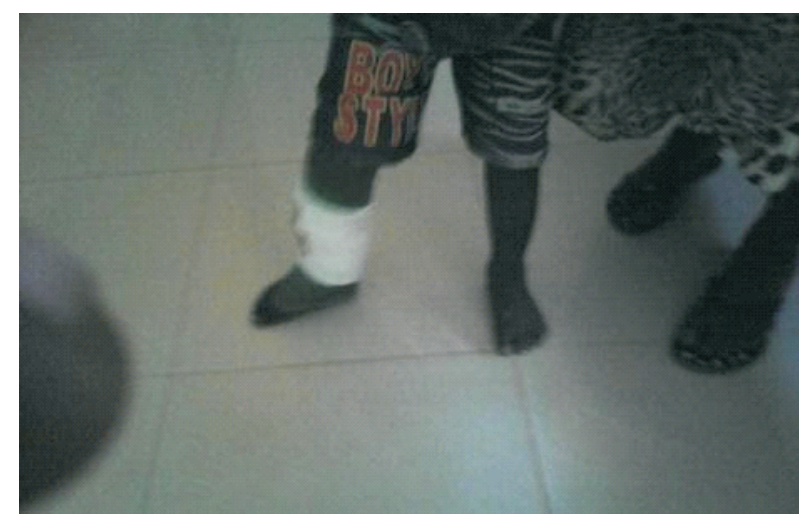

Figure 2c: Leg outside of scotch cast

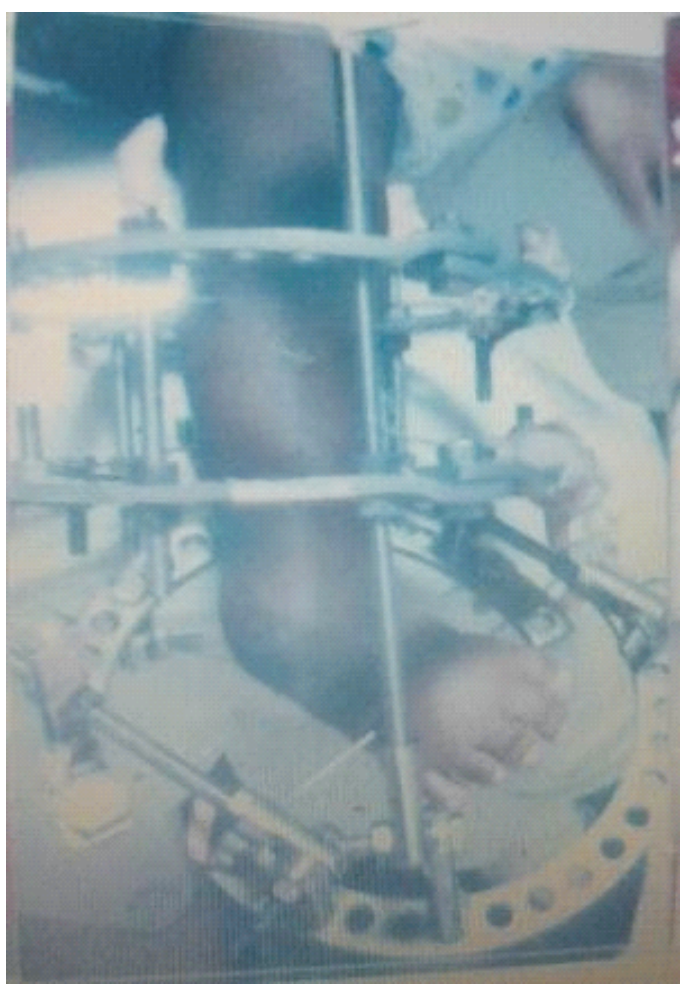

Figure 3b: Right leg and foot in Ilizarov device 


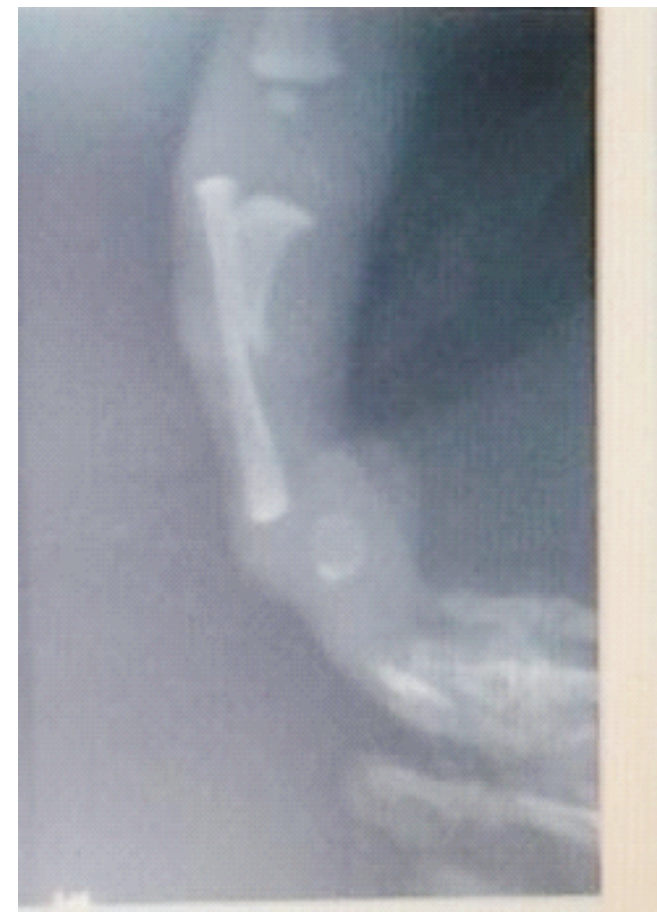

Figure 3c: Pre-op X-ray

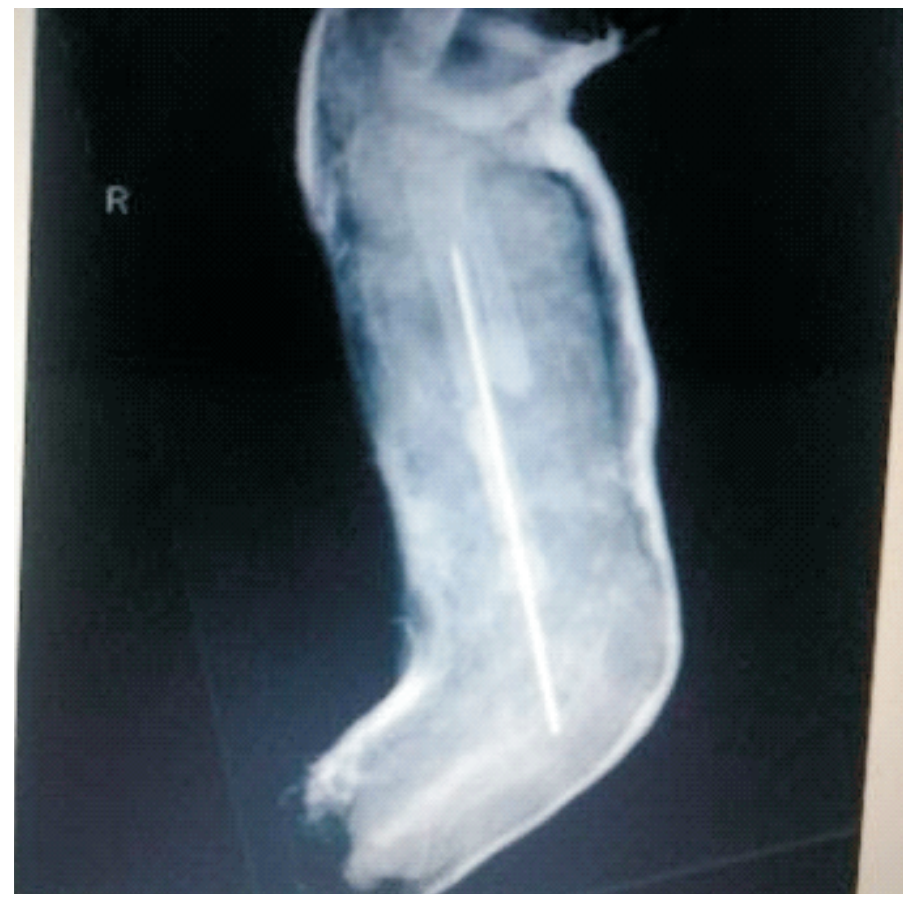

Figure 3d: Post-operation X-ray showing free fibula graft transfixed to the tibia

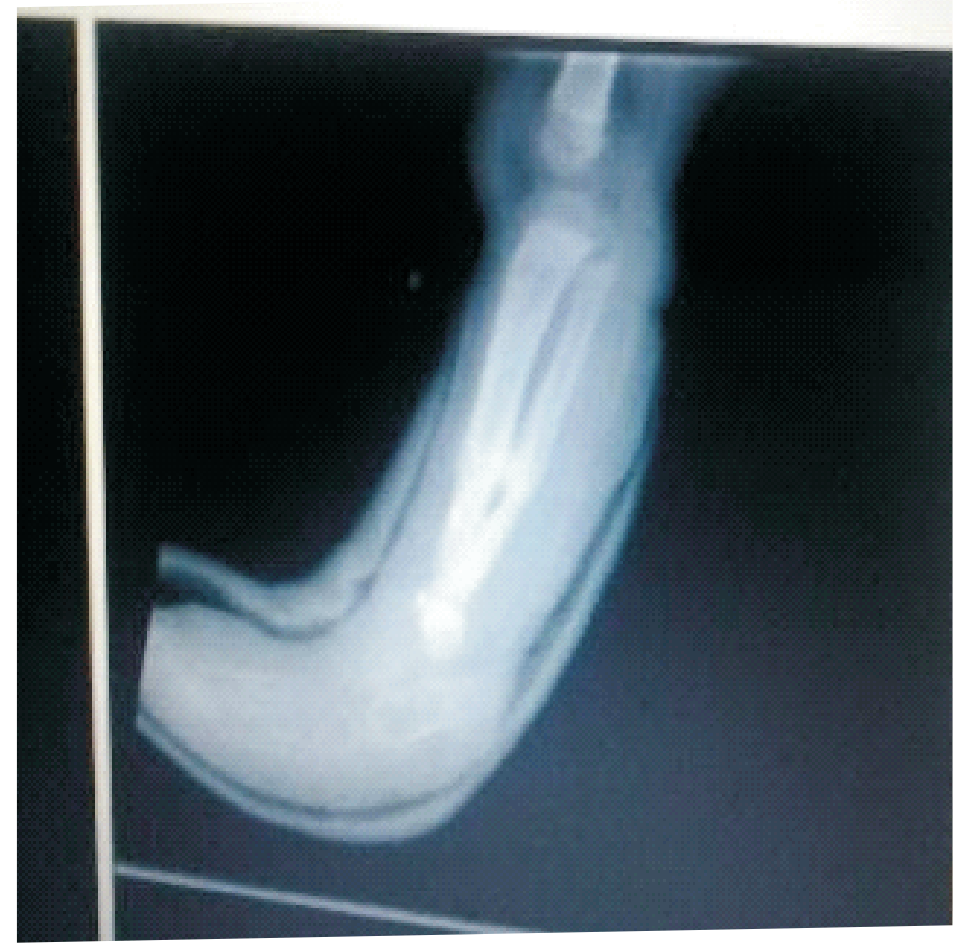

Figure 3e: Regenerated distal fibula 